\title{
Ayearon
}

\section{Librarians monitoring COVID-19 in Latin America and the Caribbean}

A year into COVID-19, the reality is that the Latin America and Caribbean region does not seem to be turning the page with regard to overcoming the pandemic. At the time of this writing, countries with previous low rates of infections such as Costa Rica, Uruguay, and several C a rib -

bean is - Monitoring COVID-19 in Latin lands are America and the Caribbean currently experie n c ing some of the worst s u r g e s in the region. $\mathrm{D}$ e a $\mathrm{t} \mathrm{h}$ rates in countries

Monitoring COVID-19 in Latin America and the Caribbean project screenshot.

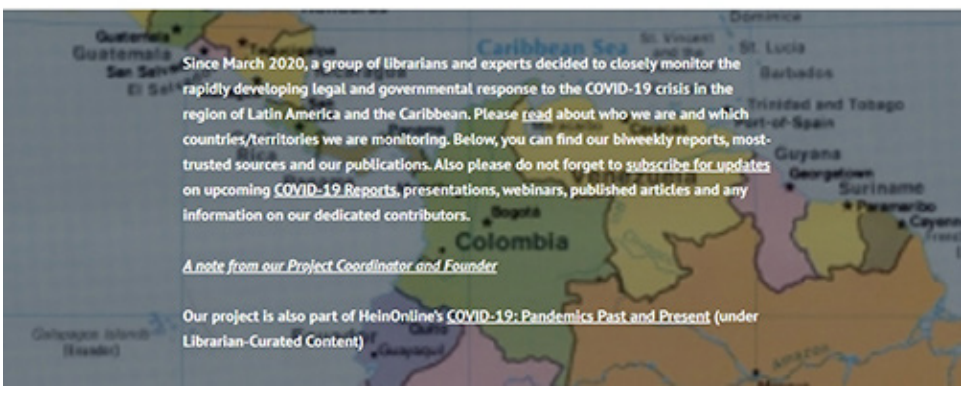

such as

Peru, Mexico, and Argentina are among the highest in the world. When the pandemic is not ravaging a country, social unrest and political instability exacerbate matters. Massive protests in Colombia and Chile, balancing between health emergency and reliance on international tourism in most Caribbean nations, political crises in Haiti and Nicaragua, and threats to the judicial systems in El Salvador and Mexico are a handful of examples of the most salient issues plaguing the region.

For over a year now, our project, Librarians Monitoring COVID-19 in Latin America and the Caribbean, ${ }^{1}$ has been closely following these situations and more. As the pandemic unfolds in unprecedented ways, the project has also had to evolve to more accurately and comprehensively capture the situation.

In this article, I will first present a short history of the project, how our goals have changed,

\section{Countries COVID-19 Reports Publications and Presentations Subseribe to Our Updates Project Members} who are our project members, and what activities we have a c c o m plished so far. Secondly, I will share $\mathrm{s}$ o $\mathrm{m} \mathrm{e}$ thoughts on the lessons learned as well as challenges that are relevant to the international academic and research community. And finally, I will touch briefly upon our next steps.

\section{Monitoring and reporting}

Back in March 2020, the region of Latin America

Marcelo Rodríguez is foreign, comparative, and international law librarian at the University of Arizona's Daniel F. Cracchiolo Law Library, email: marcelorod@ email.arizona.edu

(c) 2021 Marcelo Rodríguez 
and the Caribbean was generally not on the radar of major U.S. news and media outlets. COVID-19 was ravaging other areas of the world such as East Asia, Western Europe, and the United States. Despite the low numbers of COVID-19 infections in Latin America and the Caribbean, the overwhelming majority of governments in the region enacted comprehensive and all-encompassing national emergency plans in a matter of weeks. These abrupt and far-reaching national measures included closure of international borders which left stranded tourists and international

international Uruguay

travelers. Brazil

The stories Paraguay

of mostly Guyana

American, $\begin{aligned} & \text { Trinidad } 8 \\ & \text { Barbados }\end{aligned}$

Canadian, Martinique

European, Puerto Rico

and Israeli Costa Rica

Mexico

t o u r is t s Uanada

stranded in Switzerland

these coun- Italy

tries were the

beginning of Map of countries included in the project.
- Victoria de la Torre: Ecuador, Colombia, Venezuela

- Yasmin Morais: CARICOM + OECS

- Ana Delgado: Puerto Rico, Dominican Republic, Cuba

- Ulysses Jaen: Mexico + Central America

In order to effectively gather information and be able to tell the story with all the relevant elements and information, I considered it of utmost importance to find librarians who had a connection and/or special interest in the region.

Immediately, the first stage of our project began with gathering information from a wide variety of sources, both local and international. Each tional attention to the region.

However, as a critical observer of Latin America and the Caribbean, when governments declare states of emergency abruptly and without much transparency or accountability, it sadly raises a red flag for most corners of the region. Therefore, as librarians, we needed to track and monitor these changes and the impact on people. More importantly, by monitoring, we were bearing witness as well as sharing trustworthy information concerning a rapidly evolving and complex situation.

On-site monitoring of, and reporting on, the situation, particularly the legal and government responses to the pandemic, were the main goal of our project. To this end, I created a group of seven law librarians, each covering the following seven subregions:

- Michele Villagran: Chile, Argentina, Uruguay

- Mary Abigail Dos Santos: Brazil

- Marcelo Rodriguez: Paraguay, Bolivia, Peru librarian selected and evaluated a series of sources from national governments, news media, independent journalism, research centers, universities, civil society groups, etc. In this first part of the project, each project member had to respond to a short interview and also create a page in order to share with the audience the top sources in the subregion. This first stage was pursued from March 2020 to June 2020.

In July 2020, the group reconvened in the hope of continuing the project, especially considering the continuously deteriorating situation in the region. In order to better explain the abrupt changes and the evolving dynamics, we decided in the second stage of the project to compile brief and credible reports ${ }^{2}$ with factual information on either a particular situation or country. Another important development in this second stage was the inclusion of librarians from countries and territories throughout the entire region. ${ }^{3}$ Librarians from Argentina, Uruguay, Chile, Brazil, Paraguay, Peru, Costa Rica, Guyana, Mexico, Puerto Rico, Trinidad 
and Tobago, Martinique, and Barbados joined our project from July 2020 to January 2021. These librarians transformed the project and helped us address topics and situations that were beyond the initial focus of legal and government responses. Violence against women in Paraguay, plebiscite and immunity passports in Chile, environmental impact in Central America, currency reunification in Cuba, and online education in Mexico are among the insightful multidisciplinary reports we have compiled recently, thanks to the diversity of professional backgrounds among our project members.

\section{Lessons learned and challenges}

As we began gathering information, evaluating sources, monitor-
ing, and
reporting
on the situ-
ation, it be-
came clear
to the proj-
ect mem-
bers that we needed
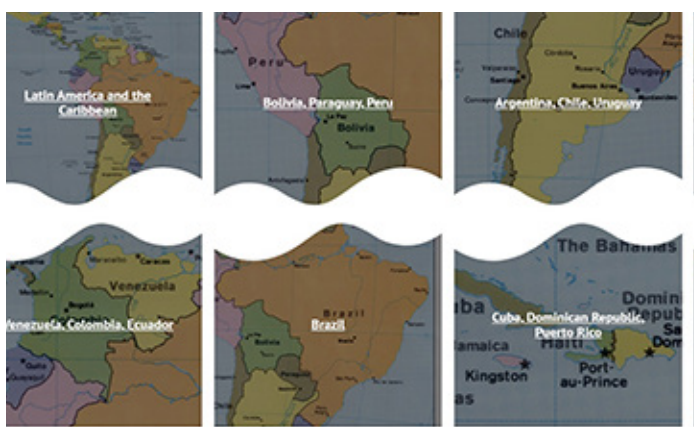

a multidis- Monitoring COVID-19 in Latin America and the Caribbean screenshot. ciplinary approach.

Without a doubt, COVID-19 has upended all areas of life in Latin America and the Caribbean. Therefore, in order to understand a particular situation, it is increasingly important to connect the dots in the story and provide a comprehensive yet succinct picture of what is really happening. When it comes to Latin America and the Caribbean, there is a tendency to isolate a particular topic or situation or country and discard or minimize the interconnection(s) of problems and even potential solutions. If we strive to truly understand the ramifications and impact of $\mathrm{CO}$ VID-19 in the region, we need to avoid the paradigm of silos in our analyses.

How can misinformation about vaccines affect electoral processes? What is the relation between national lockdowns and the usage of cryptocurrencies or increase in political corrup-

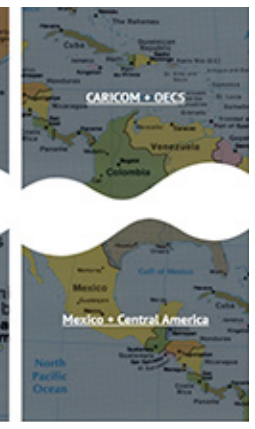

tion? How have domestic violence and femicide become an increasing danger the more the government restricts the movement of people? Are our responses to natural disaster emergencies now different in times of national states of emergency? We are only able to see the connections in these questions, thanks to the diverse backgrounds of our project members and their tremendous expertise in their areas of knowledge.

The multidisciplinary approach of our reports, especially those related to access to information brought a more regional and international perspective to the project. We were honored to count on the participation of librarians and law professions in Canada, Switzerland, Italy, and Australia. I am convinced that their perspectives and reports helped shatter the "Monroe Doctrine” mentality of understanding Latin A merica and the Caribbean mostly, if not only, through the prism of its relationship with the United States. The reality is that other regions of the world (as well as international organizations) have been, and still are, following very closely the unraveling crisis in Latin America and the Caribbean. Our project aims to capture those dynamics as well.

Perhaps the biggest challenge in our project has been access to information. COVID-19 has propelled two major issues in the region: lack of e-government infrastructure and a massive digital divide. As we began monitoring and reporting, it was clear that most governments in the region were not prepared to communicate and disseminate information in a digital-only format. When doing research and accessing information from official sources, we found that the data at times were not complete, contradictory, erroneous, and/or dated, which led us to conclude that the data were unreliable. 
The challenge of accessing and evaluating government information became even more difficult when authorities started sharing information on social media platforms. Issues with misinformation, such as the rapid spread of false and inaccurate information online, were already a major problem in the region. As librarians and academic professionals, our project members were aware of the different criteria to evaluate and curate sources and online information in general.

However, the pace of government information or data online and the unpreparedness and lack of best practices from national authorities made our work even more complicated. We had no way to effectively and accurately verify information in unofficial and alternative sources. Our local librarian counterparts and project members located in all parts of the region helped us incredibly, thanks to their local expertise as well as local networks.

The particularly challenging combination of lack of expertise on e-government practices and massive digital divide reveals another dangerous component in countries such as Nicaragua or Venezuela and even Haiti. The governments in these countries have not acknowledged the severity of the situation and have refused to compile data or provide any relevant information about the pandemic.

The data revealed the same patterns of government-sponsored misinformation in other parts of the region by either individual politicians or particular cities or provinces/states. Moreover, reporting on Nicaragua, Venezuela, and Haiti has had to rely heavily on sources located in the diaspora or from clandestine, and, at times locally, banned sources.

\section{The way forward}

A year on, and we are in the midst of concluding the second stage of our project: reporting. With upcoming reports on various Caribbean nations, as well as updates on other countries, we aim to have up to 60 reports by the end of this second stage in late summer 2021. All these reports will be compiled in a free opensource e-book, which will be available to everyone. Our hope is that this e-book becomes an important source of trusted information for anyone interested in understanding the multifaceted crisis taking place in all corners of Latin America and the Caribbean.

Furthermore, we are in the early preparation steps of launching our third stage, which will begin in September 2021. Our project aims to convene and host a free virtual international event called Conference on Access to Information: Latin America and the Caribbean (CAI:LAC).

This virtual conference aims to provide a platform to continue our conversations, including professional panels and casual conversations among project members and others in three different languages-English, Spanish, and Portuguese. In order to focus our attention in the different subregions, we strive to provide several webinars with different panelists located in these countries and abroad during the entire month of September.

We are incredibly inspired and motivated to continue what this project has already achieved. For most project members, monitoring and reporting on COVID-19 in Latin America and the Caribbean are not a theoretical exercise. For us, these reports account for what is impacting our families, friends, colleagues, neighbors, and ourselves. Our hope is that our personal connections, as well as professional expertise, are conveyed in the work we do.

If you would like to contribute to our efforts, please do not hesitate to reach out and join us.

\section{Notes}

1. Marcelo Rodriguez, "Monitoring COVID-19 in Latin America and the Caribbean" (2020), https://lawlibrariansmonitoringcovid19. com/ (accessed May 12, 2021).

2. Marcelo Rodriguez, "COVID-19 Reports on Latin America and the Caribbean" (2020), https://lawlibrariansmonitoringcovid 19 . com/2020/05/03/example-post-3/ (accessed May 21, 2021).

3. Marcelo Rodriguez, "Project Members" (2020), https://lawlibrariansmonitoringcovid 19. com/2020/10/08/project-members/ (accessed May 21, 2021). 2 